\title{
Stress Echocardiography
}

\author{
Petros Nihoyannopoulos, MD, FRCP, FACC, FESC \\ Hammersmith Hospital, NHLI Imperial College, London
}

\section{Introduction}

Myocardial ischaemia is accompanied by characteristic mechanical, electrical and perfusional abnormalities each of which has been used to detect coronary artery disease. Although coronary angiography is the gold standard for the diagnosis of coronary artery disease, the anatomical description alone does not indicate the physiological significance of stenosis. Exercise ECG, perfusion defects on technetium scans (SPECT), positron emission tomography (PET), or abnormalities of myocardial contraction detected by stress echocardiography permit the assessment of the functional severity of coronary stenoses. Echocardiography has better spatial resolution (2mm) than SPECT $(12 \mathrm{~mm})$ or PET (4mm at best) imaging. Because of this, every single myocardial region corresponding to each coronary vascular bed can be visualised from several projections such as the parasternal long-axis, short-axis or apical four- and two-chamber views (Figure 1).

What makes echocardiography unique over other imaging modalities, perhaps with the exception of magnetic resonance imaging (MRI), is its ability to visualise the entire myocardium (including the right ventricle so often ignored) from several projections so that one segment can be visualised from more than just one view. The advantage of this is that if one region is not seen sufficiently well from one projection there will be an alternative. Consequently, the success rate of stress echocardiography (often misquoted as a limitation of the technique) should be $100 \%$ for an

Received November 19, 2008

Address for correspondence: Petros Nihoyannopoulos, MD, FRCP, FACC, FESC

Hammersmith Hospital, NHLI Imperial College London,

Du Cane Road, London W12 0NN, U.K.

Telephone: +44-20-8383-3948

Fax: +44-20-8383-4392

E-mail: petros@imperial.ac.uk

(C) 2008 Japanese Society of Echocardiography experienced laboratory. As a result, stress echocardiography has acquired an unquestionable clinical role as an accurate and inexpensive stress imaging technique [1].

\section{Rationale of Stress Echocardiography}

As early as 1935 Tennant and Wiggers [2] described the loss of regional myocardial contraction during coronary artery occlusion. Studies at rest in which progressive coronary stenosis is produced in the conscious dog have shown a linear correlation between regional wall motion and subendocardial blood flow in contrast with a poor correlation with subepicardial blood flow. A 20\% decrease in blood flow produces a corresponding small reduction in systolic wall thickening [3]. This close coupling between the level of ischaemia as assessed by reduced regional blood flow and regional contraction suggests in the strongest possible way that regional wall motion is a sensitive and meaningful marker of acute ischaemic events.

In chronic coronary artery disease regional wall motion abnormalities are also sensitive markers of ischaemia [4]. It is conceivable however, that small, localised areas of regional ischaemia cannot be detected. The analysis of regional myocardial function is usually performed by averaging values from circumferential segments located inside 16 topographic regions (Figure 1). Although this approach represents a powerful way of assessing myocardial function, it may also 'dilute' small, localised areas of myocardial dysfunction in a given segment [5].

Other causes of regional wall motion abnormalities:

It is important to remember that myocardial ischaemia is not the only cause of regional myocardial dysfunction. Abnormal septal motion can also occur in several conditions (Table 1). Generally however, in these conditions endocardial excursion is abnormal but regional wall thickening remains normal. This dis- 


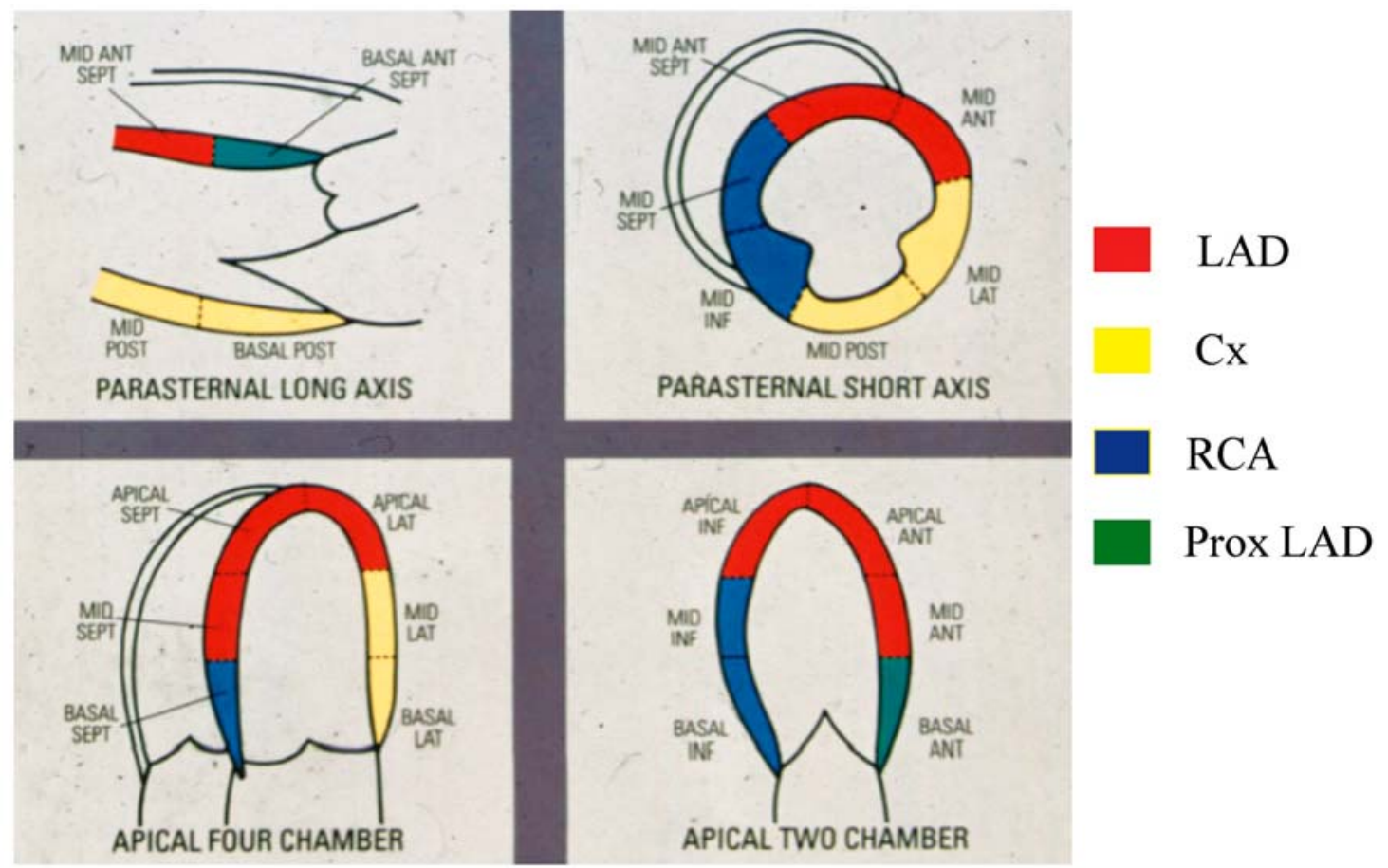

Fig. 1. Tomographic section of the heart standardised for imaging of all myocardial segments corresponding to the three vascular beds. Notice that one vascular bed can be imaged from more than one tomographic projection.

tinction permits the separation of non-ischaemic aetiology from reversible ischaemia.

\section{Methods of Stress Echocardiography}

The use of stress testing to unmask left ventricular contractile abnormalities is based on the concept of myocardial metabolic supply and demand. The demand side of the equation is highly dependent upon many factors including left ventricular pressure, volume, wall stress, heart rate and contractility. All of these parameters relate to myocardial oxygen consumption mainly through their combined effect on left ventricular wall forces linked together by the Marquee de La Place's equation (product of intracavitary pressure and radius of curvature of the myocardial segment divided by wall thickness).

\section{Exercise echocardiography:}

There are several types of stress that can be coupled with echocardiography. The fundamental advantage of exercise, particularly that of treadmill, over pharmacological stress testing is that it provides excellent natural physiological cardiovascular stress, physician's familiarity with ECG changes and symptoms and allows these to be analysed in combination with cross sectional echocardiography to detect ischaemia
Table 1. Causes of abnormal regional wall motion abnormalities

1. Right ventricular volume/pressure overload

2. Left bundle branch block

3. Wolf-Parkinson-White

4. Permanent pacing (ventricular septum)

5. Post-cardiac surgery

6. Cardiac sarcoidosis

7. Focal myocarditis

8. Aortic regurgitation

induced wall motion abnormalities. With exercise, there is an overall left ventricular fibre shortening resulting from both, the preload-dependent stretching of the myocardial fibres (Starling effect) as well as from elevated contractility due to catecholamineinduced acceleration of intracellular phosphorylation and metabolism. Its diagnostic accuracy has previously been documented in atherosclerotic coronary artery disease producing regional myocardial dysfunction in patients with angina [6-9] in contrast to patients with syndrome $\mathrm{X}$ in whom no regional wall motion abnormalities are identified [10].

The main disadvantage of using treadmill exercise with echocardiography is that imaging cannot be 
obtained throughout the stress test and can only be performed immediately after cessation of exercise. The second disadvantage is that the high respiratory and heart rates preclude optimal echocardiographic imaging when this is recorded on videotapes. For this reason digital technology must be employed with this type of stress echocardiography [11].

Digital acquisition allows ECG-triggered automatic acquisition of a preselected number of consecutive images starting from the R-wave. The computer is then programmed to capture 8 consecutive frames, 50 msec apart, resulting in the capture of $350 \mathrm{msec}$ of the cardiac cycle. This process is repeated for each desired echocardiographic projection. When all images are captured they can be played back synchronised in endless cine-loops, in single, dual-or quadscreen format. Images can be captured speedily immediately after exercise while the patient still breathes heavily with deep inspiratory and expiratory cycles. By selecting only the images captured during deep expiration (therefore the best) while discarding the poor images in deep inspiration, we end-up having excellent imaging immediately after exercise, often even better than the resting images. In this way the disadvantage of heavy respiration immediately after exercise turns to an advantage with improved imaging.

It may be argued that the time elapsing between termination of exercise and onset of imaging is responsible for failure to detect wall motion abnormalities in rapidly resolving ischaemic changes. It was found however that such rapid recovery is exceptional and occurs in only a minority of patients with mild ischaemia [12]. In two studies from our laboratory [10, 13], image acquisition started while diagnostic ECG changes were still present in all patients so that it is highly unlikely that echocardiographic imaging started too late after resolution of ischaemia. It remains possible however that when less than $20 \%$ of a transmural myocardial region becomes ischaemic this is not perceived as hypo or akinesis [14].

\section{Dobutamine stress echocardiography:}

Pharmacological stress testing is also important, particularly when patients are unable to exercise. The two leading categories of pharmacological stress testing are those producing vasodilation, such as dipyridamole and adenosine, and those producing inotropic stimulation such as dobutamine and isoprenaline. While the vasodilators were the first pharmacological agents to be used in combination with echocardiography by mimicking the nuclear stress testing rationale, they proved to be inefficient in triggering wall motion abnormalities in a satisfactory way to be clinically useful $[15,16]$.

Dobutamine stress has now emerged as the best alternative to exercise with very similar diagnostic accuracy [17-19]. Dobutamine is a catecholamine with selective beta-1 adrenoreceptor agonist activity and a relatively weak action on alpha and beta- 2 adrenoreceptors. Given intravenously, its half-life is $2.37 \pm 0.7 \mathrm{~min}$. It increases myocardial contractility with consequent increase in stroke volume and cardiac output. It also decreases central venous pressure, pulmonary arterial and capillary wedge pressures, thus reducing left ventricular filling pressures and volume. Reduction of ventricular size is particularly responsible for a decrease in wall stress. During stress echocardiography it is given intravenously starting from 5 to 40 $\mathrm{mg} / \mathrm{kg} / \mathrm{min}$ in increments of 5 or $10 \mathrm{mg} / \mathrm{kg} / \mathrm{min}$ for 3 to 5 minutes each. At these doses myocardial oxygen demand increases through an increase in heart rate, systolic blood pressure and contractility.

The main disadvantage of dobutamine stress testing is the occurrence of "paradoxical" hypotension occurring in approximately $20 \%$ of patients [20, 21]. The precise mechanism of this "paradoxical" hypotension remains unclear. However, it is likely that this is due to a cardiovascular vasodepressor reflex. Neurally mediated hypotension-bradycardia is a frequent cause of syncope as a result of cardiac vagal affronts enervating mechanoreceptors in the inferoposterior wall of the left ventricle. Vigorous myocardial contraction around a small chamber, as happens during dobutamine stress, may trigger sympatho-inhibition and increased parasympathetic discharge leading to bradycardia and hypotension [20]. Patients prone to vasodepression may have exaggerated cardiac mechanoreflex activity perhaps due to mechanoreceptor hypersensitivity. We have observed this hypotensive response to occur more frequently in small, hypertrophied and vigorously contracting ventricles rather than in the larger ventricles with extensive hypokinesia while it bares no relation to outflow tract obstruction.

Dobutamine stress testing is easier to perform than exercise echocardiography as the operator has time to optimise imaging in each projection while continuously recording throughout the infusion every myocardial region. It is however preferentially used in patients unable to exercise as an alternative test but also for the 
detection of myocardial viability. The latter has made dobutamine stress echocardiography the single most popular myocardial stressor to be used in combination with echocardiography [22-24].

\section{Feasibility of stress echocardiography:}

The perceived disadvantage of stress echocardiography is its inability to obtain meaningful information in all patients with suspected coronary artery disease. Several studies from a variety of institutions including our own, have clearly demonstrated that the success rate of stress echocardiography is or approaching $100 \%$. This is similar to either exercise or dobutamine stress (Tables 2 and 3 ).

It is common that a number of myocardial regions have not been adequately seen from one or the other view. The advantage of being able to image one coronary vascular bed from more than one projection should allow diagnostic information being obtained for all or at least $70 \%$ of myocardium in each patient in established laboratories. Stress echocardiography, like all imaging techniques is also an operator depending technique both in respect to acquisition of data and their interpretation. Proper training and experience is therefore pivotal. Automatic schemes for analysis and interpretation are not widely available at present and, as in every echocardiographic technique, require substantial expert input. Every imaging modality however is expert dependant, whether it is nuclear testing or MRI, and local expertise is widely variable, which is very similar to echocardiography.

\section{Assessing Myocardial Ischaemia}

Stress echocardiography is commonly employed for the detection of coronary artery disease. In reality however, it is the presence of myocardial ischaemia that is demonstrated, as it usually requires a $40 \%-60 \%$ narrowing of the coronary vessel in order to obtain a measurable reduction in maximal flow.

Stress echocardiography not only detects the presence of ischaemia but also can assess its magnitude (Figure 2). The severity of ischaemia can be ascertained by the degree of motion impairment from minimal (hypokinesia) to severe (akinesia), up to paradoxical systolic expansion (dyskinesia). The greater the wall thickening reduction, the greater the magnitude of ischaemia. On the horizontal axis, the extent of ischaemia can also be ascertained. The number of ischaemic zones can easily be depicted by utilising imaging of all 16 segments (Figure 1). In the presence of single ischaemic zone, the number of ischaemic segments along one coronary vascular territory would be expected to become akinetic. The greater the number of akinetic segments, the more proximal the stenosis would be. If more than one vascular bed becomes ischaemic, a multi-vessel coronary artery disease should be expected.

Finally, the timing of the wall motion abnormality being detected will also reflect the magnitude of ischaemia. The earlier the hypokinesia, the more severe the ischaemic burden would be. This grading

Table 2. Studies on Exercise Echocardiography in the Detection of Coronary Artery Disease

\begin{tabular}{lccccc}
\hline Author & Year & $\begin{array}{c}\text { Patients } \\
(\mathrm{N})(\%)\end{array}$ & $\begin{array}{c}\text { Sensitivity } \\
(\%)\end{array}$ & $\begin{array}{c}\text { Specificity } \\
\text { rate }(\%)\end{array}$ \\
\hline Berberich & 1984 & 52 & 94 & 94 & 90 \\
Armstrong & 1985 & 95 & 81 & 87 & 100 \\
Armstrong & 1987 & 123 & 87 & 86 & 100 \\
Labovitz & 1987 & 73 & 81 & 92 & 94 \\
Ryan & 1988 & 64 & 78 & 100 & 100 \\
Crouse & 1991 & 228 & 97 & 64 & 100 \\
Marwick & 1922 & 179 & 84 & 86 & 100 \\
\hline
\end{tabular}

Table 3. Dobutamine Stress Echocardiography in the Detection of Coronary Artery Disease

\begin{tabular}{lccccc}
\hline Author & Year & $\begin{array}{c}\text { Patients } \\
(\mathrm{N})(\%)\end{array}$ & $\begin{array}{c}\text { Sensitivity } \\
(\%)\end{array}$ & $\begin{array}{c}\text { Specificity } \\
\text { rate }(\%)\end{array}$ \\
\hline Mazeika & 1992 & 50 & 81 & 93 & 100 \\
Segar & 1992 & 85 & 95 & 82 & 100 \\
Marcovitz & 1992 & 141 & 96 & 66 & 100 \\
Marwick & 1993 & 217 & 72 & 83 & 100 \\
\hline
\end{tabular}




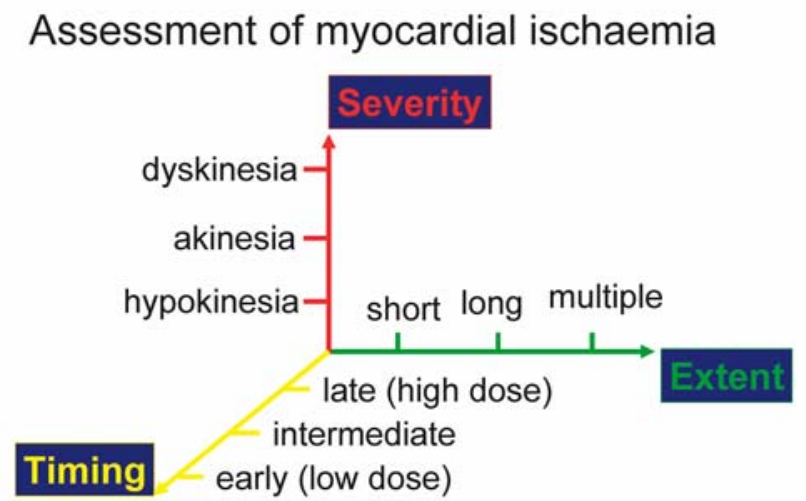

Fig. 2. Assessing the magnitude of myocardial ischaemia in a three-dimensional model. Severity is assessed as the degree of reduced systolic wall thickening (vertical axis), the extent as the number of ischaemic segments along one or more coronary vascular beds (horizontal axis), and the earlier one region becomes hypokinetic, the greater the severity of coronary stenosis.

however is valid mainly in patients undergoing continuous echocardiographic imaging such as during dobutamine infusion, while for post-exercise echocardiography this may not be applicable.

The diagnostic accuracy of stress echocardiography relies mostly on the arbitrary angiographic cut-off value to define "significant" stenosis. This is often performed visually. The purely anatomic-functional approach of comparing myocardial ischaemia in coronary artery disease patients may itself be insufficient and wrongly estimating sensitivities and specificities of the test when only the presence of stenosis is considered. The value of careful quantification of stenosis severity in the prediction of a positive stress echocardiography test has repeatedly been emphasised [25, 26]. The best cut-off point for predicting wall motion abnormalities during bicycle ergometry appears to be in the region of $52 \%$ stenosis with a minimal lumen diameter of $1.13 \mathrm{~mm}$ in patients with single vessel coronary artery disease. Complex coronary stenotic lesion with irregular borders and/or multiple irregularities however are more likely to be associated with a positive stress test than patients with symmetric lesions [27].

\section{Clinical Settings}

Stress echocardiography is appropriate where exercise ECG is unlikely to provide a satisfactory answer to the clinical question being posed and should improve the selection of patients for tertiary referral. Speed and convenience strengthen the economic argument in favour of this technique, the reliability of which was emphasised early on by results that were highly concordant if not better than gated pool imaging and SPECT perfusion imaging.

Stress echocardiography emerges as a vital modality for screening high-risk patients before major peripheral vascular surgery [28], orthopaedic surgery or in patients with chronic renal failure [29]. Others [30] emphasised the value of exercise echocardiography after coronary artery bypass surgery in predicting compromised vascular supply.

Assessment of patient's prognosis is important in an era when clinical decision-making must be rendered in a cost-effective manner. A number of studies have demonstrated that the one and two year prognosis following a normal exercise or dobutamine stress echocardiogram is excellent and at least equivalent if not better to that seen following normal thallium scintigraphy [31].

\section{Assessing Myocardial Viability}

In the setting of ischaemia, loss of myocardial contractile function may be due to myocardial necrosis, stunning or hibernation. While myocardial necrosis usually alludes to irreversible myocardial dysfunction, stunning and hibernation reflect reversibility of myocardial function. It is therefore important to be able to differentiate the potential reversibility of such myocardial dysfunction. A variety of non-invasive methods are undergoing investigation and validation for detecting viability in akinetic or severely hypokinetic myocardial regions including SPECT with 201Tl, $99 \mathrm{mTc}$ sestamibi, PET imaging of regional flow and Flabeled 18FDG uptake as well as assessment of inotropic contractile reserve with dobutamine stress echocardiography.

There is no doubt that similar information can be obtained by other nuclear techniques when the appropriate expertise is present. However, it seems that Thallium SPECT generally overestimates the probability of postoperative myocardial recovery of dyssynergic regions [32]. It has a low specificity (48\%) and low positive predictive value (33\%). As expected therefore, its sensitivity is high (89\%) with high negative predictive value (94\%). Against this, dobutamine stress has a somewhat lower sensitivity (74\%) with similar negative predictive value (93\%) but a higher specificity (95\%) and positive predictive value ( $85 \%)$. 


\section{Contrast Echocardiography}

Contrast enhancement is used extensively in diagnostic and clinical radiology. Modalities such as X-ray, computed tomography, magnetic resonance imaging and nuclear scintigraphy regularly rely on the introduction of foreign material into tissue in order to improve the contrast resolution in the image. The development of contrast media in echocardiography has been slow and sporadic. Only recently transpulmonary contrast agents have become readily available for clinical use [30]. The primary indication for the use of contrast echocardiography is at present to improve endocardial border delineation in patients in whom adequate imaging is difficult. In coronary artery disease patients in whom particular attention should be focused on regional myocardial contraction, clear endocardial definition is crucial. Intravenous contrast agents can improve endocardial delineation at rest [34] and with stress [35].

\section{Detection of myocardial perfusion:}

The major use of transpulmonary contrast agents is in the detection of myocardial perfusion, or lack of it. We recently proposed that this is indeed possible in patients following myocardial infarction (Figure 3) [36]. Intravenous injection of Sonazoid ${ }^{\mathrm{TM}}$ (NycomedAmersham, Oslo, Norway) consistently produced myocardial opacification in patients with previous myocardial infarction and allowed delineation of myocardial perfusion abnormalities. The anatomical location of each myocardial perfusion abnormality detected by contrast echo correlated well with that of
SPECT perfusion imaging and wall motion abnormalities. However, the results indicated also that assessment of myocardial perfusion by either SPECT or myocardial contrast is subject to attenuation artifacts, which predominate in the inferior wall for SPECT and the anterior and lateral walls for echocardiography [36].

According to the ischaemic cascade, perfusion deficits precede contractile dysfunction during stress. This means that the sensitivity of perfusion modalities would be higher than functional tests such as echocardiography or MRI. However, with the combination of intravenous contrast injection during dobutamine stress echocardiography, the sensitivity of stress echocardiography can increase without the loss of specificity. In Figure 4 is a patient at peak dobutamine stress where a clear perfusion deficit at the apex can be seen (black zone) while the contractile function is still preserved.

\section{Stress Echocardiography Laboratory}

Echocardiography has dramatically expanded over recent years with more and more physicians requesting studies. Its major advantage of being safe and cheap has become a disadvantage as more and more people use it, many inappropriately trained, and therefore with progressively increasing chance of inaccurate reports. The British Society of Echocardiography has issued guidelines for training which are essential for those performing and interpreting echocardiography [33]. Stress echocardiography is steadily going down a similar road except that it is more difficult to perform
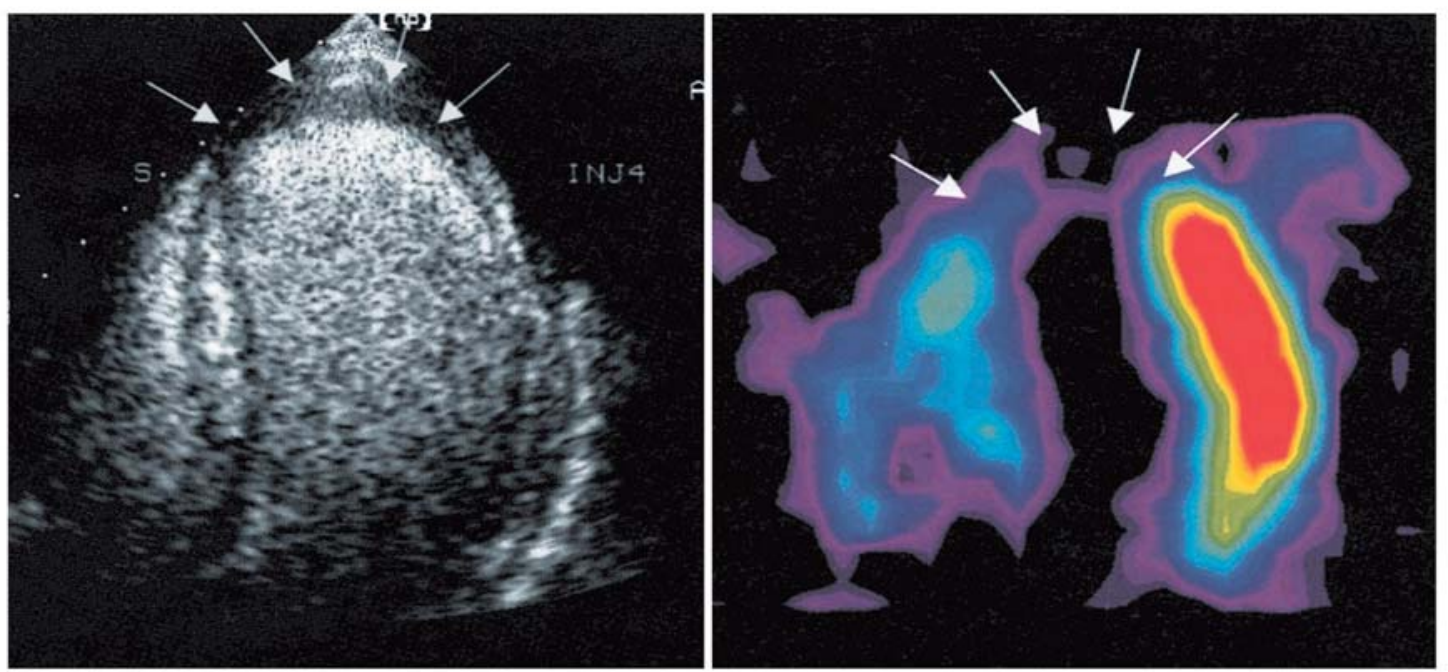

Fig. 3. Myocardial Perfusion Apical 4-Chamber 


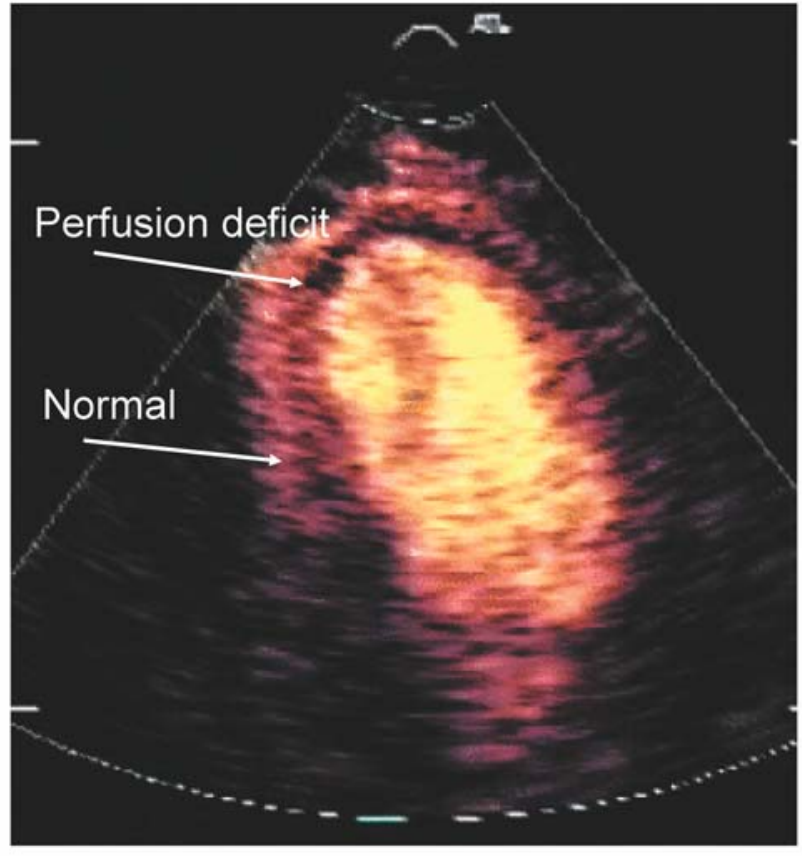

Fig. 4.

and even more difficult to interpret. Because of the radiation hazards, nuclear stress testing is confined to experts generally, thus containing the irresponsible use of stress testing with radioisotopes. There is no such protective net with stress echocardiography, which is open to wide use including non-qualified staff. It is therefore of pivotal importance to increase individual expertise steadily and cautiously in a protected centre before using it as a decision-making investigation. It is recommended to perform at least 100 exams under the supervision of an expert reader in a high-volume laboratory, and ideally with the possibility of angiographic verification, before starting stress echocardiography on a routine basis. Maintenance of competence requires at least 100 stress echocardiography exams per year. To highlight the clinical utility and safe use of stress echocardiography, the European Association of Echocardiography has published an expert consensus document on stress echocardiography [37].

\section{Conclusions}

Stress echocardiography is a versatile technique for diagnosis and management assessment of patients with known or suspected coronary artery disease. To be trusted, it needs dedicated equipment and a responsible team who provide such a service on a regular basis. Stress echocardiography is today the best (most cost-effective and risk-effective) possible imaging choice while it keeps this modality in the hands of cardiology without the need of purchasing an alternative service from a separate department. It should not replace stress ECG, which is cheap and ideal for the triage of patients with suspected coronary disease.

\section{Reference}

1. Iliceto S, Galiuto L, Marangelli V, Rizzon P. Clinical use of stress echocardiography. Factors affecting diagnostic accuracy. Eur Heart J 1994; 15: 672-80.

2. Tennant R, Wiggers CJ The effect of coronary artery occlusion on myocardial contraction Am J Physiol 1935; 12: 351

3. Gallagher KP, Matsuzaki M, Osakada G, Kemper S, Ross J Jr. Effect of exercise on the relationship between myocardial blood flow and systolic wall thickening in dogs with acute coronary stenosis. Circ Res 1983; 52: 71629.

4. Leighton RF, Nelson D, Brewster P. Subtle left ventricular asynergy with completely obstructed coronary arteries. Am J Cardiol 1983; 52: 693

5. Lima JAC, Becker LC, Melin JA, et al. Impaired thickening of nonischaemic myocardium during acute regional ischaemia in the dog. Circulation 1985; 71: 1048-59.

6. Marwick TH, Nemec JJ, Pashkow FJ, Stewart WJ, Salcedo EE. Accuracy and limitations of exercise echocardiography in a routine clinical setting. J Am Coll Cardiol 1992; 19: 74-81.

7. Armstrong WF. Exercise echocardiography: Ready, willing and able. J Am Coll Cardiol 1988; 11: 1359-61.

8. Limacher MC, Quinones MA, Poliner LR, Nelson JG, Winters WL, Jr, Waggoner AD. Detection of coronary artery disease with exercise two-dimensional echocardiography. Circulation 1983; 67: 1211-8.

9. Armstrong WF, O'Donnell J, Dillon JC, et al. Complementary value of two dimensional exercise echocardiography to routine treadmill exercise testing. Ann Intern Med 1986; 105: 829-35.

10. Nihoyannopoulos P, Kaski JC, Crake T, Maseri A. Absence of myocardial dysfunction during stress in patients with syndrome X. J Am Coll Cardiol 1991; 18: 1463-70.

11. Marwick TH, Nemec JJ, Pashkow FJ, Stewart WJ, Salcedo EE. Accuracy and limitations of exercise echocardiography in a routine clinical setting. J Am Coll cardiol 1992; 19: 74-81.

12. Presti CF, Armstrong WF, Feigenbaum H. Comparison of peak and postexercise echocardiographic imaging in evaluation of coronary artery disease. J Am Soc Echo 1988; 1(2): 119-26.

13. Nihoyannopoulos P, Marsonis A, Joshi J, Athanassopoulos 
G, Oakley CM. Magnitude of silent ischaemia is greater in painful than in painless myocardial ischaemia: an exercise echocardiographic study. J Am Coll Cardiol 1995; 25: 1507-12.

14. Pandian NG, Skorton DJ, Collins SM, et al. Myocardial infarct size threshold for two-dimensional echocardiographic detection: sensitivity of systolic wall thickening and endocardial motion abnormalities in small versus large infarcts. Am J Cardiol 1985; 55: 551.

15. Margonato A, Chierchia S, Cianflone D, et al. Limitations of Dipyridamole-echocardiography in effort angina pectoris. Am J Cardiol 1987; 59: 225-30.

16. Mazeika P, Nihoyannopoulos P, Joshi J, Oakley CM. Uses and limitations of high dose dipyridamole stress echocardiography for evaluation of coronary artery disease. Br Heart J 1992; 67: 144-9.

17. Sawada SG, Segar DS, Ryan T et al. Echocardiographic detection of coronary artery disease during dobutamine infusion. Circulation 1991; 83: 1605-14.

18. Sear DS, Brown SE, Sawada SG, Ryan T, Feigenbaum H. Dobutamine stress echocardiography: correlation with coronary lesion severity as determined by quantitative angiography. J Am Coll Cardiol 1992; 19: 1197-202.

19. Marwick T, Willemart B, D'Hondt A, et al. Selection of the optimal myocardial dysfunction and malperfusion. Comparison of dobutamine and adenosine using echocardiography and 99mTc-MIBI single photon emission computed tomography. Circulation 1993; 87: 345-54.

20. Tanimoto M, Pai RG, Jintapakorn W, Shah PM. Mechanisms of hypotension during dobutamine stress echocardiography in patients with coronary artery disease. Am J Cardiol 1995; 76: 26-30.

21. Lieberman EB, Heinle SK, Wildermann BA, Waugh RA, Kisslo JA, Bashore TM. Does hypotension during dobutamine stress echocardiography correlate with anatomic or functional cardiac impairment? Am Heart J 1995; 129: 1121-6.

22 Barilla F, Gheorgiade M, Alam M, Khaja F, Goldstein S. Low dose dobutamine in patients with acute myocardial infarction identifies viable but not contractile myocardium and predicts the magnitude of improvement in wall motion abnormalities in response to coronary revascularisation. Am Heart J 1991; 122: 1522-31

23. Cigarroa CG, de Filippi CR, Brickner E, Alvarz LG, Wait MA, Grayburn PA. Dobutamine stress echocardiography identifies hibernating myocardium and predicts recovery of left ventricular function after coronary revascularisation. Circulation 1993; 88: 430-6.

24. Pierard LA, De Landsheere CM, Berthe C, Rigo P, Kulbertus H. Identification of viable myocardium by echocardiography during dobutamine infusion in patients with myocardial infarction after thrombolytic therapy: comparison with positron emission tomography. J Am Coll Cardiol 1009; 15: 1021-31.

25. Salustri A, Arnese M, Boersma E, Cornel JH, Baptista J, Flhendy A, Ten Cate FJ, de Feyter PJ, Roelandt JRTC, Fioretti PM. Correlation of coronary stenosis by quantitative coronary arteriography with exercise echocardiography. Am J Cardiol 1995; 75: 287-90.

26. Arnese M, Salustri A, Fioretti PM, Cornel JH, Boersma E, Reijs AEM, DeFeyter P, Roelandt JRTC. Quantitative angiographic measurements of isolated left anterior descending coronary artery stenosis. Correlation with exercise echocardiography and technetium-99m 2Methoxy isobutyl isonitrile single-photon emission computed tomography. J Am Coll Cardiol 1995; 25: 1486-91.

27. Lu C, Picano E, Pingitore A, Sicari R, Tongiani R, Baratto M, Palmieri C, Marzilli M, L'Abbate A. Complex coronary lesion morphology influences results of stress echocardiography. Circulation 1995; 91: 1669-75.

28. Krivokapich J, Child JS, Gerber RS et al. Dobutamine stress echocardiography for assessment of cardiac risk before non-cardiac surgery. Am J Cardiol 1993; 71: 64651.

29. Reis G, Marcovitz PA, Leichtman AB, Merion RM, Fay WP, Werns SW, Armstrong WF. Usefulness of dobutamine stress echocardiography in detecting coronary artery disease in end-stage renal disease. Am J Cardiol 1995; 75: 707-10

30. Kafka H, Leach A, Fitzgibbon GM. Exercise echocardiography after coronary artery bypass surgery: correlation with coronary angiography. J Am Coll Cardiol 1995; 25: 1019-23.

31. Sawada SG, Ryan T, Conley MJ, et al. Prognostic value of a normal exercise echocardiogram. Am Heart J 1990; 120: 49-55.

32. Arnese M, Cornel JH, Salustri A, Maat APWM, Elhendy A, Reijs AEM, Ten Cate FJ, Keane D, Balk AHMM, Roelandt JRTC, Fioretti PM. Prediction of improvement of regional left ventricular function after surgical revascularisation. A comparison of low dose dobutamine echocardiography with 201Tl single-photon emission computed tomography. Circulation 1995; 91: 2748-52.

33. Monaghan MJ, Anderson V, Chambers, J, Leech G, Martin M, Nihoyannopoulos P, Westgate C, Wilde P. Training in echocardiography. B Heart J 1994; 71: 2-5

34. Crouse LJ, Cheirif J, Hanly DE, Kisslo JA, Labovitz AJ, Raichlen JS, et al: Opacification and border delineation improvement in patients with suboptimal endocardial border definition in routine echocardiography: results of phase III Albunex multicenter trial. J Am Coll Cardiol 1993, 22: 1494-500.

35. Ikonomidis I, Holmes E, Narbuvold H, Bolstad B, Muan B, Nihoyannopoulos P. Left venticular wall motion asses- 
ment and endocardial border delineation after intravenous injection of Infoson ${ }^{\mathrm{TM}}$ during dobutamine stress echocardiography. Coronary Artery Disease, 1998; 9: 56776.

36. Jucquois I, Nihoyannopoulos P, D' Hontdt A-M, Roelants V, Robert A, Melin JA, Glass D, Vanoverschelde J-LJ. Comparison of myocardial contrast echocrdiography with NC100100 and Tc-99m sestamibi single photon emission computed tomography for detection of resting myocardial perfusion abnormalities in patients with previous myocardial infarction. Heart 1999; (in press).

37. Sicari R, Nihoyannopoulos P, Evangelista A, Kasprzak J, Lancellotti P, Poldermans D, Voigt J-U, Zamorano JL. Stress echocardiography expert consensus statement. Eur J Echocardiogr 2008; 9:415-37. 